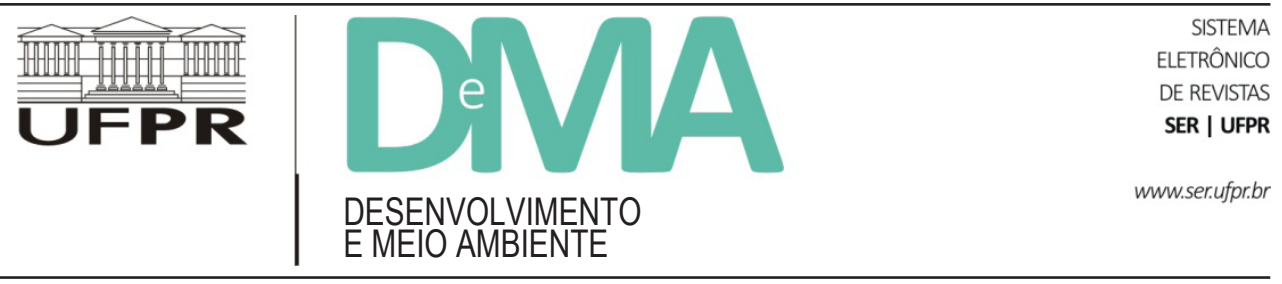

\title{
Decisões civilizatórias e campo ambiental: a norma como parte do emaranhado
}

\section{Civilizing Decisions and the Environmental Field: Law and Entanglement}

\author{
David Malheiro FADUL ${ }^{1 *}$, José Edmilson de SOUZA-LIMA ${ }^{1}$ \\ ${ }^{1}$ Programa de Pós-Graduação em Meio Ambiente e Desenvolvimento (PPGMADE), Universidade Federal do Paraná (UFPR), Curitiba, PR, Brasil. \\ *E-mail de contato: dmf030@gmail.com
}

Artigo recebido em 31 de outubro de 2015, versão final aceita em 24 de outubro de 2016.

RESUMO: Este artigo enquadra-se no diálogo ambiental contemporâneo, a partir do campo jurídico, com considerações epistemológicas e metodológicas. Toma-se o campo ambiental como ponto de partida para explorar as contribuições e limites do campo jurídico nesse diálogo, à luz da escola do Realismo Jurídico. A ideia-força deste artigo é explorar a real influência do Direito sobre a sociedade e investigar se é possível promover mudança socioambiental por meio de mudanças na legislação. Essa pergunta penetra o campo ambiental através dos conceitos de "emaranhado" e "decisão civilizatória". Conclui-se que as diferentes correntes epistêmicas oferecem diferentes soluções à crise ambiental e que, a partir do Realismo Jurídico, o Direito pode ser visto como imbricado no emaranhado.

Palavras-chave: desenvolvimento; complexidade; epistemologia jurídica.

ABSTRACT: This article relates to the contemporary environmental dialogue, from the perspective of the Legal Field, with epistemological and methodological considerations. The Environmental Field is taken as a starting point to explore the contributions and limitations of the Legal Field in such dialogue, in the light of Legal Realism. The idea of this article is to explore what the real impact of law on society is, and investigate whether it is possible to promote social and environmental change through changes in legislation, relating this question to the Environmental Field thru the ideas of 'entanglement' and 'civilizing decision'. We conclude that different epistemic schools offer different solutions to the environmental crisis and that, by considering Legal Realism, a law can be seen as interwoven in the entanglement.

Keywords: development; complexity; legal epistemology. 
"O todo é maior que a soma das partes."

(Aristóteles)

\section{Introdução}

As reflexões contidas neste artigo relacionam-se ao diálogo ambiental contemporâneo em um viés epistemológico e metodológico, enfocando o objeto do campo ambiental como ponto de partida para explorar as contribuições e limites do campo jurídico nesse diálogo. Anteriormente, buscamos encontrar no campo ambiental (Fadul \& Souza-Lima, 2013) contribuições que poderiam ser apreendidas pelo campo jurídico. Neste artigo, no entanto, invertemos a questão e propomos lançar bases para entender quais contribuições o campo jurídico pode oferecer ao campo ambiental.

A ideia-força deste artigo é explorar qual a real influência do Direito (ou melhor, do processo de criação, interpretação e aplicação da lei) sobre a sociedade. Em outras palavras: investigar se é possível promover mudança socioambiental por meio de mudanças na legislação.

Trata-se de pergunta raramente formulada, mas rotineiramente respondida. Muitas pesquisas jurídicas apenas tomam por garantida a influência da lei e enfocam ou sua interpretação ou a propositura de novas leis. É importante frisar que, no campo jurídico - especialmente em seu núcleo hegemônico -, há grande resistência em considerar a influência de fatores que não a lei. Nesse sentido, o presente artigo intenta ser tanto uma tentativa de diálogo com o campo monocultor como, também, um conjunto de considerações para os participantes do campo ambiental emergente que tenham interesse em incluir considerações jurídicas em suas pesquisas, mas não estão afixados, originariamente, no campo jurídico. A relevância dessa pergunta para o campo ambiental constitui-se a partir das ideias de "emaranhado" e "decisão civilizatória".

Um ponto-chave que pretendemos delinear é o do fenômeno jurídico como espaço de manifestação da coevolução (Norgaard, 1994). Tal noção, amiúde desconsiderada na episteme estruturalista ${ }^{1}$, pode ser contribuição de relevo ao campo ambiental se permitir a identificação de decisões civilizatórias - as quais seriam invisíveis caso se observassem apenas as normas positivadas.

A episteme jurídica que embasará o presente estudo será o Realismo Jurídico (Ross, 2000). Assim, vale adiantar o que essa escola propõe. O que marca o Realismo Jurídico - atravessando os diversos autores que contribuíram com sua construção - e o diferencia do estruturalismo é a proposta de que a validade das normas não advém de suas inter-relações estruturais, mas de sua efetiva aplicação na realidade empírica (Ross, 2000). As pesquisas jurídicas, conforme hoje preponderam, com todas as opiniões "doutrinárias" e suas controvérsias, para o realista, não passam de retórica ou, na melhor das hipóteses, sugestões ao julgador acerca de como decidir as lides. Para o realista, as normas são visíveis apenas nas práticas dos tribunais e a lei é a lei viva, conforme se manifesta empiricamente.

O termo "sistema", quando usado, busca dialogar com os autores ligados à teoria dos sistemas, e o sentido está próximo ao entendimento de

\footnotetext{
${ }^{1}$ A inspiração para a escolha do termo "estruturalismo" vem de Bobbio (2007), que elegeu o termo em detrimento do consagrado "positivismo" para evitar confusão com sua própria proposta (chamada funcionalista), que também seria "positivista" caso se considere o termo lato sensu. Por estruturalismo entende-se a corrente da epistemologia jurídica que vê como objeto da "ciência do direito" determinar a "validade" da norma (Ross, 2000).
} 
Norbert Wiener (1948) e Ludwig von Bertalanffy (1975), como ente isolado e com partes coordenadas capazes de realizar processo transmutativo de informações. A busca desse diálogo justifica-se a partir da potencial fecundidade do uso do conceito de sistema jurídico, que se entende como mais que coletividade dos órgãos ligados à função jurisdicional, mas deve incluir também todos os pontos de (co)influência (porosidade) entre o sistema e o restante do corpo social.

O outro marco deste estudo, o conhecimento ambiental, apesar de não ser difundido entre pesquisadores jurídicos, vem ganhando força, nas últimas décadas, como campo emergente. Os pontos de partida para nossa compreensão do campo ambiental encontram-se em Aímola (2002) e Souza-Lima (2012; 2013). Tratando-se de um campo eminentemente interdisciplinar, são inerentes ao ambiental a busca por facilitar o diálogo entre diversos campos e o encorajamento do pesquisador a aproximar-se, ou mesmo sair, das fronteiras de seu campo-base para a ele retornar oxigenado, propiciando assim a troca de conceitos e princípios.

Este artigo será divido em duas partes, de acordo com os dois âmbitos nos quais o Direito pode contribuir com o conhecimento ambiental: o prático e o teórico. A segunda parte, por sua vez, dividir-se-á em duas seções; a primeira dialogará com as noções de "emaranhado" e "decisão civilizatória"; e a segunda explorará como o campo jurídico pode auxiliar em um entendimento mais amplo de tais noções.

Por fim, vale ressaltar que as considerações deste artigo são estritamente acadêmicas e voltadas aos pesquisadores que, ligados ao campo jurídico, estejam predispostos a aventurar-se em pesquisas de caráter ambiental - ou, inversamente, que estejam ligados ao ambiental, mas sintam a necessidade de tecer considerações jurídicas. Sempre que tratarmos de questões concretas, é preciso ter como pano de fundo as pesquisas jurídicas e ambientais. Por exemplo, ao nos debruçarmos sobre a pergunta central deste estudo - ou seja, como a legislação afeta o sistema social -, o fazemos para trazer à luz uma premissa que está oculta, ou seja, nos perguntamos acerca do alcance prático e teórico de pesquisas que desconsideram essa pergunta nevrálgica. É nesse sentido que contrapomos o Realismo Jurídico a outras epistemes do campo, como forma de ampliar o escopo das pesquisas voltadas ao ambiental, restando claro que a aplicação de uma episteme realista não tem intenção ou capacidade de tornar a lei um instrumento mais ou menos eficaz.

\section{Tensionando o campo ambiental: decisão civilizatória}

A ideia-força deste item é tensionar o conceito de emaranhado ambiental, buscando expor seus limites e potencialidades. Em que pese o "emaranhado" e o conceito de "decisões civilizatórias" terem pontos de aproximação, pretendemos deixar claro de pronto que os consideraremos como distintos, embora relacionados. As considerações que teceremos a seguir embasam-se, naturalmente, no entendimento de alguns autores que já se debruçaram sobre questões ambientais, e, de forma alguma, tais considerações pretendem-se universalmente aceitas.

Assim, de pronto apresenta-se uma questão: não seria o princípio da (co)evolução uma saída para a episteme jurídica hegemônica? Ou seja, já que a lei é resultado de um processo legislativo que está inserido na sociedade, não seria possível defender que a promulgação de uma lei, per se, já indica a existência de um vetor? Embora essa questão não seja um ponto central do presente estudo, 
ela deve ser preliminarmente considerada, de forma a evitar conflitos interpretativos. Para entendermos essa questão, precisamos levar em conta que o emaranhado, embora inextricável, é passível de ser entendido, mesmo que apenas em caráter precário - se não fosse assim, não seria possível fazer qualquer consideração acerca do emaranhado. Por conta disso, algumas noções podem ser delineadas de forma mais ou menos clara. No contexto presente, há dois pontos de interesse: primeiro, sabe-se que as sociedades não são homogêneas - seja no espaço ou no tempo - e, portanto, não se pode supor que um vetor, pelo simples fato de existir, seja idêntico em todo o sistema social. Segundo, as leis são elaboradas por um sistema - o legislativo - e, como é característico, um (sub)sistema tem autonomia - mas não isolamento - em relação ao meio e, por conta disso, os vetores que compõem o sistema não são idênticos aos vetores que compõem o sistema social, apesar de relacionados a estes.

Nos campos monocultores pode haver a tendência, particularmente no núcleo epistêmico duro, de tentar isolar certos objetos que seriam pertinentes ao campo e estariam, portanto, dentro de suas fronteiras. Uma das características do campo ambiental é a consideração de que os vetores tidos como objetos isolados pelos demais campos podem ser vistos como partes inextricáveis de um "emaranhado" de fatores que (co)influenciam-se mutuamente, bem como ao sistema social. As decisões civilizatórias que veremos no item seguinte podem ser consideradas um resultante da constante disputa de interesses que constitui o emaranhado. Elas seriam, assim, análogas a pontos de coexistência que existiriam no sistema social como um todo, não apenas no espaço de disputas dos campos de conhecimento.
Não se deve entender, por outro lado, que o pesquisador ambiental deva ser uma espécie de especialista em generalidades, que detenha conhecimentos irrestritos e busque dar conta de todos os fatores imagináveis em sua pesquisa. Trata-se apenas de recusar determinações a priori sobre o que é ou não relevante ao campo ambiental e entender a realidade concreta da pesquisa como fator empírico determinante de quais vetores serão ou não considerados. Por vezes, o pesquisador tem de buscar nas produções especializadas dos campos monocultores as inspirações necessárias à completude de seu próprio estudo.

Para clarear essa questão, proporemos alguns exemplos. Os primeiros são de caráter hipotético, e o último foi retirado de uma pesquisa empírica. Por óbvio, o exemplo concreto será infinitamente mais complexo que os hipotéticos, haja vista a estrutura naturalmente caótica do emaranhado (Ardoino, 2010).

Primeiramente, por um lado, seria óbvio que a escolha civilizatória entre uma sociedade que pratique formas tradicionais de agricultura e uma que utilize técnicas modernas implicasse alterações diferentes no ambiente que ocupam. Nesse caso, tratar-se-ia de a decisão civilizatória implicar uma influência direta da sociedade sobre o ambiente.

Por outro lado, questões de política social, tais como a emancipação feminina, podem ser - e por vezes são - consideradas totalmente desconectadas do ambiental, mas, se entendermos o ambiente lato sensu, não se pode simplesmente ignorar esses vetores sociais. Há pesquisas que sugerem (NarayanParker, 2002) que a emancipação feminina é a forma mais imediata de superar condições de miséria em países que eufemisticamente fossem chamados de "em desenvolvimento". De fato, a $\mathrm{OECD}^{2}$ indica

\footnotetext{
2 Organization for Economic Cooperation and Development. Disponível em: < http://www.oecd.org/dac/povertyreduction/50157530.pdf $>$. Acesso em 17 nov. 2013.
} 
o incentivo de oportunidades iguais entre os sexos como ferramenta de superação da pobreza, e o Grameen (banco dos pobres de Bangladesh), estabelecendo práticas que se ajustam a essa premissa, oferece microcrédito a cooperativas de mulheres (Souza-Lima \& Knechtel, 2012). Considerando essa possibilidade (de a emancipação feminina ser fator de redução da pobreza), o vetor em questão estaria ligado a vetores econômicos, os quais, por sua vez, (co)influenciariam vetores ambientais.

A Figura 1 (esquerda) representa a percepção clássica acerca dos vetores, como entidades relacionadas, mas independentes. A Figura 1 (direita) indica uma compreensão ambiental do emaranhado.

Para ilustrar a hipótese descrita, proponhamos uma sequência de eventos, forçosamente especulativa: considere-se um sistema social cujo estado inicial seja o de exclusão absoluta da população feminina de atividades econômicas, excetuando-se as atividades domésticas. Há, então, a introdução de políticas de incentivo à emancipação (empowerment) feminina, o que leva a uma maior participação de mulheres, especialmente jovens adultas, nas atividades agrícolas. Com tal participação, há um aumento na produtividade e tal sistema social passa a um novo estado, no qual seja possível sustentar uma maior população, o que, por sua vez, requer maior utilização do solo e, eventualmente, pode levar a seu esgotamento, o que seria um efeito ambiental.

Note-se que, em diversos pontos, os acontecimentos poderiam ter se encaminhado de forma diferente. Os vetores contrários à emancipação (empowerment) poderiam ter prevalecido; uma má colheita poderia haver desconstruído o projeto em seu início, ou mudanças políticas mais amplas poderiam ter tornado a própria existência do grupo impossível. Da mesma forma, o resultado ambiental poderia haver sido positivo, na forma de uma solução ou mitigação de um problema ambiental prévio, ou poderia ser o agravamento de um problema existente ou uma combinação dos anteriores, ou, ainda, não geraria impacto ambiental - stricto sensu - algum. O que importa é ressaltar a imprevisibilidade e o processo de confluência caótica do emaranhado, ou seja, tais considerações não devem ser vistas como uma proposta exata acerca de uma situação concreta, uma vez que está na própria natureza do emaranhado a dificuldade de deslindá-lo; trata-se, sim, de um exemplo hipotético que ilustra como a coinfluência entre os vetores pode gerar resultados imprevistos.

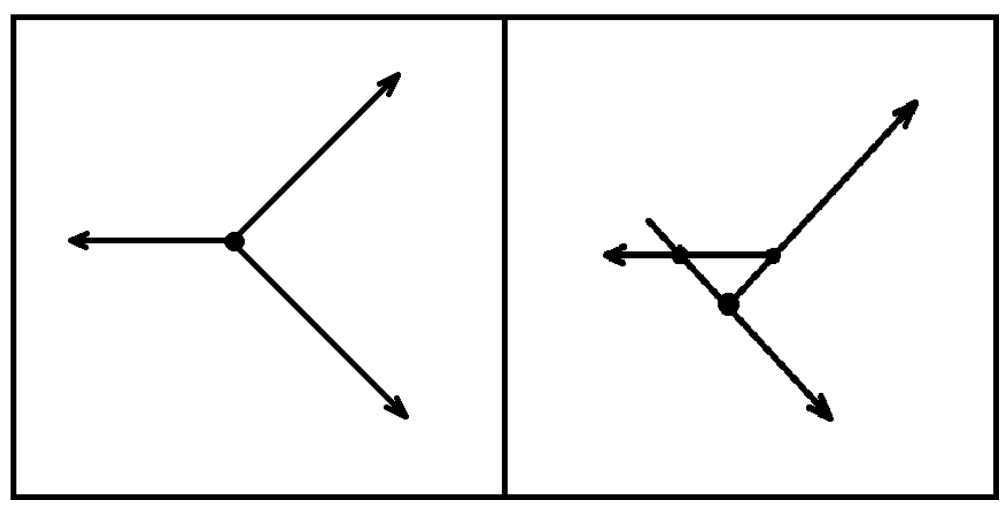

FIGURA 1 - Vetores clássicos (esquerda) e emaranhado ambiental (direita) 
$\mathrm{Na}$ realidade social concreta, é amiúde impossível afirmar com qualquer grau de segurança que certa política ou certo fato teve este ou aquele efeito. Empiricamente, mesmo a realidade social mais simples é sempre suscetível a mudanças e influências simultâneas, de forma a nunca restar claro qual causa, especificamente, gerou qual efeito. Um exemplo como o anterior serve apenas como um modelo para clarear o conceito que se busca explicar e não como descrição.

Agora, contrastemos o caso hipotético anterior a um exemplo concreto, obtido a partir de pesquisa realizada na bacia do rio Verde (Souza-Lima, 2013, p. 156):

Em estudo envolvendo pesquisadores das áreas socioculturais, sociotécnicas e biofísicas (CUNHA et al., 2011), o objetivo mais amplo era verificar se a bacia do Rio Verde (Figura 2), localizada na região metropolitana de Curitiba - Paraná, Brasil - estava sob iminência de assimilar processos de eutrofização [O aumento de algas microscópicas próximas à superfície impede a penetração de luz na água e, por sua vez, a realização da fotossíntese nas camadas mais profundas, provocando a morte de algas que estão abaixo da superfície. A grande concentração de algas mortas favorece o aumento das bactérias decompositoras, que consomem muito oxigênio para realizar a decomposição. A falta de oxigênio na água provoca a morte de peixes e outros organismos aeróbicos. Com a falta de oxigênio, a decomposição de matéria orgânica, que inicialmente era aeróbica, passa a ser anaeróbica, aumentando a produção de gases tóxicos, como o gás sulfídrico $\left(\mathrm{H}_{2} \mathrm{~S}\right)(\mathrm{ODUM}$, 1983; RICKLEFS, 1996)]. No bojo deste amplo programa interdisciplinar de pesquisa foi realizado um estudo (SOUZA-LIMA et al., 2009), tomando como referência a sociologia ambiental, com o propósito de captar a representação social do risco ambiental dos habitantes da bacia hidrográfica em estudo. O pressuposto implícito e derivado dos campos disciplinares biofísicos era o de que havia um risco ambiental iminente, o de uma possível eutrofização das águas da bacia. Em certa medida este pressuposto trazia de forma subjacente uma denúncia em relação às práticas agrícolas dos habitantes, todas elas centradas na utilização de produtos agroquímicos e fertilizantes. A pergunta que se pretendia responder era: "qual a percepção de risco ambiental dos habitantes da bacia do Rio Verde?".

Notamos primeiramente que, ao contrário do exemplo hipotético, nessa pesquisa não se observou um momento de transição entre dois estados do sistema social. Como deve ocorrer na maioria dos estudos concretos, limites de tempo e de recursos impõem a necessidade prática de enfocar apenas um estado do sistema em pauta.

No âmbito biofísico, a pesquisa enfocou a situação ambiental corrente, em específico quanto à possibilidade de eutrofização da bacia do rio Verde. Era pressuposto que as práticas agrícolas dos habitantes fossem, pelo menos parcialmente, responsáveis pela situação da bacia. Note-se que essas "práticas" são indicadoras de uma decisão civilizatória, causadora de imediato impacto ambiental. O processo de eutrofização, caso viesse a ocorrer, seria uma alteração estrutural no sistema ambiental, a qual geraria um novo vetor ambiental. De que maneira tal vetor afetaria o emaranhado e, por consequência, o sistema social, no entanto, é algo extremamente difícil de prever e não foi questão de interesse na pesquisa concreta. Haja vista que a bacia não é fonte de subsistência - nem está diretamente relacionada a outras atividades econômicas -, é possível que o novo vetor ambiental não viesse a ter qualquer influência imediata sobre os habitantes, mas também poderia acontecer de a contaminação ter efeitos deletérios sobre a saúde da população. Tal imprevisibilidade está na natureza do emaranhado e serve de conto caucionário aos pesquisadores que tenham pretensões oraculares.

No âmbito sociológico, a pesquisa enfocou a situação corrente, tentando estabelecer, via entre- 
vistas, a percepção social acerca do risco ambiental iminente (Souza-Lima, 2013, p. 156-157):

Os relatos dos entrevistados - representação social do risco ambiental - evidenciaram o temor dos entrevistados não em relação ao suposto risco de eutrofização das águas da bacia, mas, dentre outros, em relação à legislação ambiental e às ameaças oriundas do ambiente sociocultural, a legislação ambiental, por exemplo.

Tivesse a pesquisa revelado uma percepção social negativa em relação ao risco ambiental (risco, lembremos, gerado por práticas da própria comunidade), poder-se-ia inferir a existência de um vetor contrário à decisão civilizatória em pauta. Mas, como a percepção social não era negativa em relação aos riscos ou práticas, e, sim, em relação à legislação ambiental, isso indica (sem determinar) que, naquela comunidade, tal vetor não faz parte do emaranhado (ou, se faz, tem forma incipiente), independentemente de como a questão da contaminação da bacia seja entendida na sociedade mais ampla. Para trazer as considerações ao campo jurídico, isso indica que a consciência jurídica (Ross, 2000) desse grupo não entende as práticas ambientais correntes como "criminosas" e, portanto, que a aplicação de leis relativas à sua restrição pode encontrar resistência do sistema social local.

A ideia-força desta seção foi tensionar o campo ambiental. Buscou-se mostrá-lo como um emaranhado que deriva (sem ser determinado) de diversos subcampos, dentre estes o subcampo jurídico, no qual nos aprofundaremos no item 3. A partir de certos marcos teóricos (Aímola, Souza-Lima, Norgaard, etc.), delineamos o emaranhado não como um todo harmônico, mas, sim, como realidade complexa a partir da qual suas partes - os vetores estudados pelos campos monocultores - estão constantemente emergindo para, em seguida, reimergir, em um continuado processo de autoafirmação e consequente autotranscendência. Logo, tensionar o emaranhado significa mostrá-lo em crise. E se, como este breve estado da arte demonstra, ele está em crise, assim também todos os subcampos se propõem a apresentar "soluções". Dentre essas "soluções", vamos, mais adiante, considerar as construídas à luz do subcampo jurídico, em particular, do Realismo Jurídico. Antes, porém, faremos algumas considerações acerca das decisões civilizatórias.

\subsection{Decisões civilizatórias e o emaranhado}

Compreende-se por decisões ou escolhas civilizatórias a resultante da interação entre dois ou mais vetores do emaranhado ambiental (Fadul \& Souza-Lima, 2014, p. 64):

[...] é apreendido como um emaranhado envolvendo escolhas e decisões civilizatórias, derivadas do ambiente sociocultural e do próprio ambiente biofísico. Trata-se, portanto, de um "objeto" que reclama abordagens que transcendam as fronteiras dos campos disciplinares instituídos. Este esclarecimento justifica as inquietações deste trabalho diante da dificuldade do conhecimento jurídico incorporar, em sua episteme, fundamentos que permitam diálogos com outros campos disciplinares.

O conceito de "escolha civilizatória", em uma forma incipiente, já aparece em Aímola (2002, p. 160):

As interações básicas entre um organismo vivo, ou um sistema de organismos, incluídos os humanos, e o seu ambiente se dão através de trocas de matéria, energia e informação, e em geral essas trocas mantêm o sistema vivo. Algumas dessas interações são ações dos organismos sobre o seu ambiente e as respostas desses meios àquelas ações. 
Essa definição incorpora os elementos essenciais do que nominamos "decisões civilizatórias", mas encontra limite em seu foco individual. Enquanto qualquer interação de um sistema biológico altera o meio, em geral transformações profundas dependem de um conjunto de interações individuais, capazes de afetar a estrutura do sistema além do ponto de autorregeneração (Aímola, 2002). Por exemplo: o despejo de dejetos em um rio, se realizado por um grupo bastante reduzido de indivíduos, não seria necessariamente capaz de alterar a estrutura do sistema "rio"; no entanto, se uma comunidade realizar o despejo de dejetos no rio, este pode passar do ponto de autorregeneração.

Deve-se deixar claro que, enquanto é possível que um único indivíduo gere uma alteração profunda em dado ambiente - realizando, por exemplo, uma queimada -, mesmo essa ação deve ser pensada em termos sociais, no sentido de que o praticante deve contar com algum grau de conivência da sociedade na qual está inserido. Se o indivíduo que pratica certo ato encontrar efetiva punição, legal ou de qualquer outra natureza, e o ato em pauta for raramente repetido, não se pode dizer que se trate de decisão civilizatória, mesmo que o impacto ao ambiente seja considerável.

Assim, só se pode ter como ação realmente individual capaz de alterar o meio de forma profunda aquela que pode ser realizada anonimamente ou em caráter excepcional. $\mathrm{O}$ que ora chamamos de "decisão civilizatória" não é o ato em si, mas a resultante dos vetores socioambientais, que torna possível (ou impossível) a prática continuada de uma ação.

Por conseguinte, o que entendemos por "decisões civilizatórias" é uma “decisão" atuada por todo um grupo, uma comunidade, uma sociedade, que, por seu escopo coletivo, tem o potencial de alterar profundamente o sistema ambiental ao qual o sistema social está ligado. Naturalmente, o termo "decisão" não deve ser entendido como uma escolha consciente, como quando o termo é aplicado a um indivíduo, mas como resultante de inúmeras decisões individuais.

Um exemplo bastante expressivo de decisão civilizatória seria a "revolução neolítica" ou "revolução agricultural". Originalmente, todas as sociedades humanas viviam como caçadores-coletores, isto é, como grupos nômades de aproximadamente 500 indivíduos que acompanhavam manadas de diferentes animais, caçando-os e deles extraindo sua subsistência. Adicionalmente, colhiam frutos e sementes como fonte complementar de alimentos. Chama-se "revolução neolítica" a passagem de uma sociedade caçadora-coletora para uma agrária ou pastoril, com a subsequente domesticação de diversas plantas e animais (Simmons, 2007). Apesar de haver considerável disputa entre historiadores, arqueólogos e antropólogos acerca de questões especificas, estima-se que o processo de sedentarização iniciou-se há cerca de 12 mil anos e decorreu em diferentes ritmos em diversas partes do mundo, havendo, até o presente, sociedades que se mantêm, em grau maior ou menor, nômades - mais notadamente, os aborígines australianos.

Conforme esperamos que esteja claro, a decisão civilizatória só pode ser compreendida no contexto da sociedade que a realiza (o que não exclui a possibilidade de diferentes grupos se (co) influenciarem), ou seja, cada grupo social toma a decisão civilizatória de permanecer caçador-coletor - que é o estado original do sistema - ou passar a uma subsistência agrária ou pastoril. Essa escolha representa o marco zero a partir do qual outras decisões civilizatórias se sucedem.

Note-se que o processo de sedentarização está de acordo com a definição apresentada de decisão civilizatória, tratando-se de uma "decisão" social 
e que representa clara mudança na maneira como o sistema social afeta e é afetado pelo ambiente. De fato, o potencial de alterar o ambiente ao qual o sistema está ligado é marca essencial de uma decisão civilizatória.

Uma situação que vale ressaltar - devido a sua constância nas sociedades multiculturais modernas - é quando certa prática ocorre frequentemente, mas, por outro lado, contra ela, há discursos extremamente críticos e bastante disseminados em certos quartéis da sociedade. Mais uma vez, as queimadas podem ser um exemplo. Nesses casos, a prática deriva de uma decisão civilizatória, enquanto o discurso que lhe é contrário indica a existência de outro vetor, que se lhe opõe. Essa oposição manter-se-á enquanto nenhum dos vetores tornar-se forte o bastante para anular o outro. Quando e se isso ocorrer, a prática será fortemente reduzida, ou o discurso cessará de ter apelo social, ou o ambiente será alterado além do ponto de regeneração.

\section{O campo jurídico e o emaranhado ambiental}

Entendendo-se o campo ambiental como derivado de um emaranhado em constante crise, é apenas natural que os diversos campos de conhecimento, a partir da percepção dessa "crise" venham apresentar soluções que possam dar-lhe conta. A ideia-força desta seção é expor o que singulariza o campo jurídico no contexto ambiental, a partir das diversas concepções epistêmicas. Por exemplo: o estruturalismo reivindica para o campo a autoridade de se pronunciar sobre a norma positivada e, por meio desta, busca dar conta da "crise ambiental".

O campo ambiental teve sua origem na necessidade de buscar soluções para problemáticas ambientais concretas e lidar com elas (Aímola, 2002), e o Direito positivo, sendo o instrumento brandido pelo legislador para alcançar dada função social, tem óbvia importância para a obtenção de resultados positivos na prevenção e controle dos "problemas ambientais". Nessa perspectiva, embasada em uma episteme funcionalista (Bobbio, 2007), os demais campos monocultores identificariam o problema e apontariam soluções, e o sistema jurídico, de posse desses dados, elaboraria leis que se enquadrassem à estrutura legal vigente. Tais leis, por sua vez, seriam encaminhadas ao legislador, na forma de propostas. O legislador, então, sopesaria a futura lei em face das questões políticas de peso e, por fim, se veria promulgada a nova norma, a qual passaria a ter efeito sobre a sociedade e ser aplicada por juízes e tribunais.

Mesmo o pesquisador mais ingênuo percebe que o proposto acima não passa de uma descrição ideal, incompatível com a realidade concreta. No entanto, desconsiderar de pronto a influência de uma norma positiva é tão ingênuo quanto tomá-la como garantida. Ao desenvolvermos as contribuições teóricas que o campo jurídico tem a oferecer, deslindaremos mais tal questão. Por ora devemos deixar aberta a possibilidade de, mesmo sem atribuir-lhe a onipotência tão cara às pesquisas estruturalistas, seja possível que a lei e seu processo interpretativo influam em circunstâncias concretas e, entendendo-se seus limites, a promulgação de leis específicas pode ser instrumental na resolução de problemas sociais.

Nesse sentido, o diálogo entre o jurídico e o ambiental pode oferecer indicações importantes acerca da noção de desenvolvimento, e, sobre tal questão, convém dedicar algumas considerações.

Assim, é preciso tensionar nossas compreensões acerca da capacidade do Estado em, por meio da lei-ou, mais especificamente, do sistema jurídico -, gerar ou favorecer o crescimento econômico, 
o desenvolvimento humano ou, ainda, de forma mais ampla, promover alterações nos padrões de comportamento de uma sociedade. Nesse sentido, pretende-se explorar a relação entre a lei positiva e a sociedade, buscando identificar a capacidade de normas legais abstratas afetarem e influenciarem ações e decisões concretas, alterando, assim, o emaranhado ambiental. No entanto, no campo jurídico, discussões acerca de alterações no sistema social tomam a forma de debates a respeito de um suposto "desenvolvimento".

Ao se tratar do tema "desenvolvimento", especialmente se lhe acrescentam o epíteto "sustentável", corre-se o risco de tender para mitificação e abstração. Em geral, um pesquisador entende "desenvolvimento" como uma alteração em um dado sistema social que ele considere, em algum sentido, positiva. Como qualquer sistema, os sociais encontram-se em constante transformação - por "transformação" entende-se a passagem de um estado do sistema para um estado diverso -, derivada da constante coevolução e (co)influência de vetores sociais e biológicos. Apesar de algumas transformações, especialmente se consideradas de forma isolada, serem universalmente aclamadas como positivas - a diminuição da mortalidade infantil é um exemplo -, em diversos casos, uma transformação implica a imposição, ao menos temporária, de um interesse sobre outro. Nesses cenários mais comuns, o desenvolvimento para uns significa tragédia para outros. Tal dicotomia costuma ser resolvida pela desqualificação dos interesses de um dos grupos: os ambientalistas declarando que os empresários só estão interessados na obtenção de lucro e os empresários alegando que os ambientalistas são contrários ao crescimento econômico, para mencionar um par de discursos, à guisa de exemplo.

Além de circunstâncias nas quais diferentes grupos compreendem a mesma transformação em sentidos totalmente diversos, há outro fator de complexificação no tema "desenvolvimento": trata-se de transformações cujos resultados práticos se ramificam além do previsto por alguns ou por todos os atores relevantes - esses casos serão explicados mais adiante, ao descrevermos as escolhas ou decisões civilizatórias.

Portanto, dar-se-á preferência ao termo "transformação" em lugar de falarmos em desenvolvimento, por tratar-se de termo com maior amplitude. Assim, a pergunta que motiva este item é como e até que ponto a lei afeta a transformação do sistema social.

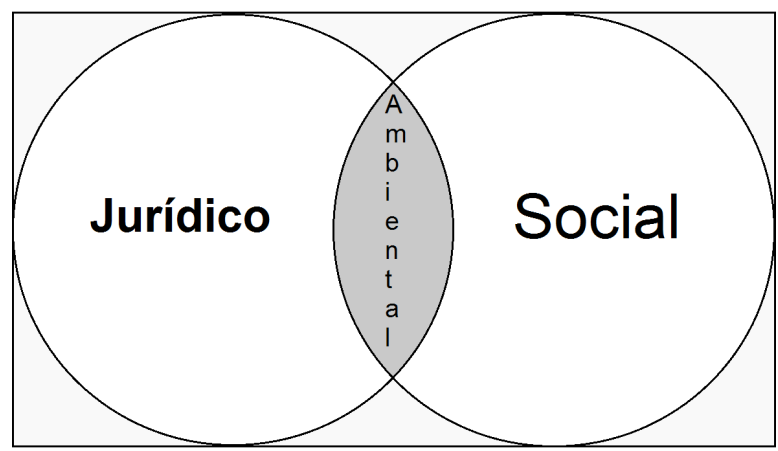

FIGURA 2 - O desenvolvimento a partir do campo ambiental não pode ser imposto.

Uma consideração que requer imediato esclarecimento é que não se pretende elaborar acerca da potencial capacidade do aparato estatal de contribuir de forma a melhorar as condições objetivas de dada parcela da sociedade. Se os agentes do Estado instalarem e mantiverem em funcionamento um hospital onde antes não havia um e o equiparem com capitais humano e tecnológico necessários a sua operação, não resta dúvida de que esse ato geraria considerável melhora às condições da população, que passaria a ter acesso ao tratamento médico (sem embargo de essa decisão encontrar oposição ou resistência de outros grupos, os quais 
poderiam, por exemplo, demandar que tal hospital fosse construído em sua própria região).

Muitos juristas, com acerto, chamariam a atenção para o fato de que a construção desse hospital, pelo Poder Público, deveria ser embasada na promulgação de uma lei, já que o princípio da legalidade administrativa prevê que a administração pública só pode agir conforme previsto em lei. Logo, diriam esses juristas, um hospital, ou uma escola, ou um quartel não serão construídos, a menos que alguma lei os preveja.

Tais considerações poderiam facilmente confundir pessoa mais ingênua a pensar que, no caso descrito, a lei estaria afetando diretamente a vida e comportamentos dos elementos do sistema social, mas se trataria de mera falácia. É bastante óbvio que, em se tratando da construção ou instalação de um serviço público, não é a lei, mas, sim, o serviço que afeta o sistema social. A necessidade de lei reguladora, nesses casos, é uma tentativa de garantir uso bom e adequado dos recursos sociais e em nada ajuda - e de fato atrapalha - a instalação do serviço em si.

Ademais, o Estado pode facilmente afetar a economia, para melhor ou pior, por meio de políticas monetárias e fiscais e, assim, por via indireta, atingir profundamente o sistema social. Mas, como economistas por vezes afirmam, nem sempre é possível prever com qualquer grau de precisão quais serão os efeitos de dada alteração nos vetores econômicos (Mankiw, 2001).

Porém, o que se buscará deslindar, presentemente, é a influência das leis que pretendem regular diretamente o comportamento de indivíduos e empresas. Vejamos um exemplo: veja-se o artigo 121 do Código Penal, que prevê pena de reclusão de seis a 20 anos pela prática de homicídio simples. Trata-se, sob uma perspectiva funcionalista (Bobbio, 2007), de lei que visa coibir o comportamento de "matar outrem", na expectativa de que a abstinência da prática de tal ação garanta melhora na qualidade de vida da população. Nesse exemplo, nota-se que, de fato, a grande maioria dos participantes do grupo social não pratica o crime de homicídio. Comparemos com o artigo 49 da Lei 9.605/98, que prevê pena de três meses a um ano a quem, culposamente, danificar planta ornamental. Apesar de a Lei 9.605/98 ser válida tanto quanto o Código Penal, esse artigo 49 é raramente aplicado na prática dos tribunais. Ocorre que, enquanto o homicídio é crime na consciência jurídica popular (Ross, 2000), a destruição de planta ornamental não o é.

Em última instância, a busca de transformação social a partir de uma pesquisa jurídica isolacionista pode tender para o utópico e o metafísico. Deve-se levar em conta que, no que tange à lei, nem sempre é razoável esperar que sua mera promulgação altere a realidade social da maneira esperada. Para que o campo jurídico possa contribuir para solucionar questões sociais concretas, far-se-á necessário abraçar o empírico como ponto de partida - possivelmente a partir de uma episteme realista (Ross, 2000) - e avaliar, no caso concreto, se a norma é ou não efetiva na realidade social em que se pretende aplicável.

\subsection{Os vetores jurídicos como componentes do emaranhado}

No aspecto teórico, a contribuição da pesquisa jurídica seria ajudar a revelar e demonstrar as decisões civilizatórias de dado grupo social, mas, para tanto, faz-se necessário estabelecer se a lei positiva representa um vetor social ou uma decisão civilizatória. Esta pesquisa representaria o marco zero na inserção do Direito no diálogo ambiental.

É preciso, a princípio, esclarecer que não se pretende, no presente artigo, abraçar de forma 
unívoca quaisquer teorias simplificadoras. Enquanto expressamos com clareza que o sistema jurídico deve ser visto como um "sistema aberto" e, portanto, afetado pelos vetores sociais, não se pretende, a partir daí, decretar a priori quais sejam esses vetores. Essa observação é importante devido à tendência - preponderante em certos quartéis - de atribuir ao "interesse econômico" uma capacidade de controle absoluto sobre a legislação. No presente artigo, no entanto, enquanto se reconhece a influência de vetores econômicos, entende-se que estes não são os únicos a afetar o sistema jurídico e, ademais, que a existência de diversos vetores econômicos (os quais, amiúde, estão em conflito entre si) impede o termo "interesse econômico", bem como seus muitos sinônimos, de ter um referente (Frege, 1892) definido. Ao contrário dessa concepção mais ingênua, em uma perspectiva realista - ou mesmo funcionalista - do Direito, considerar-se-ia que, entre os "interesses econômicos" e a lei positiva, há o legislador, que, em geral, priorizará seus próprios interesses, e que, entre a lei positiva e a sociedade, há o juiz - e todo o sistema jurídico -, também dotado de interesses próprios.

Outro entendimento, igualmente ingênuo, é que o ordenamento jurídico teria efeito imediato e absoluto sobre a sociedade, bastando ao legislador promulgar lei para que comecem a surgir efeitos no corpo social. Essa perspectiva materializa-se em noções, frequentemente ditas e repetidas, tais como: "A lei é boa, só falta cumpri-la".

\section{Potencialidades e limites das soluções propostas pelos campos monocultores}

A ideia-força desta seção é expor as potencialidades e limites das "soluções" apresentadas pelo campo jurídico, a partir das correntes epistêmicas que o compõem.
Em uma perspectiva estruturalista/funcionalista, o campo jurídico é apreendido de forma isolada do emaranhado. Por consequência, arroga-se o direito de impor "soluções" de fora, com vistas a resolver os problemas do campo ambiental. Resulta dessa imposição de "fora para dentro" que tanto o campo jurídico quanto o ambiental tornam-se sistemas mortos nessas perspectivas epistêmicas.

Os realistas (Ross, 2000), por outro lado, demandam que a norma esteja imbricada na consciência e no modus vivendi dos membros de dada sociedade e manifeste-se nas decisões concretas de juízes e tribunais. Essa escolha de recorte é, em si mesma, um limite do Realismo Jurídico, mas trata-se de uma perspectiva que parece oferecer uma abordagem fundamentalmente diferente (em relação às anteriores). Na perspectiva realista, o campo jurídico pode ser tomado como um subcampo do campo ambiental e, por consequência, o sistema jurídico pode ser entendido como parte constituinte do emaranhado. Se, na outra abordagem, o campo jurídico reivindica o direito de propor normas com vistas a "solucionar" a crise do campo ambiental, aqui o subcampo jurídico é apreendido não como "solução" a priori, mas como potencial parte efetiva da própria crise ambiental. Por intermédio do Realismo Jurídico, a norma não é sublimada, como se estivesse isenta das contaminações da realidade sociocultural, mas tomada como parte constituinte do emaranhado que singulariza o campo ambiental. Não se trata mais de um Direito que impõe soluções de fora, mas de um Direito que se junta aos demais vetores em um emaranhado vivo, em transformação contínua, em constante crise.

É importante notar que a episteme realista, enquanto propensa a reduzir o isolacionismo próprio da episteme estruturalista, não afeta a autonomia do campo jurídico. Nesse viés, podemos esclarecer a distinção entre isolamento e autonomia: 
isolamento representando uma (tentativa de) separação do ambiente e autonomia significando a demanda de tratar prioritariamente de um aspecto do ambiental. Assim, o Realismo Jurídico, se aplicado, não desnaturaria o campo jurídico. Ele apenas o abriria a novas influências.

Naturalmente, essa proposta de buscar no Realismo Jurídico inspirações para pesquisas jurídicas ligadas ao ambiental não deve ser vista, ela própria, como solução última para todos os males. Ao contrário, o pesquisador que optar por esse caminho deve fazê-lo estando ciente de que, em uma pesquisa realista, apresentar-se-ão novos problemas e desafios - como, por exemplo, desvendar como uma pesquisa jurídica pode lidar com o caráter imbricado do emaranhado ambiental. Esses problemas, como é característico nas pesquisas empíricas, não têm soluções a priori, demandando considerações a partir dos casos concretos.

\section{Considerações finais}

Assim, percebe-se que os modelos apriorísticos mostram-se insuficientes para abraçar os indicadores de realidade. É possível - e mesmo provável - que, em um regime democrático, a (co)influência entre lei e sociedade dê-se de forma complexa, não sendo nem o caso de a sociedade conseguir sempre fazer valer sua "consciência jurídica" (Ross, 2000), nem de o legislador ser capaz de impor sua visão sobre a sociedade. Ambas as direções de (co)influência apenas misturam-se ao emaranhado ambiental, resultando disso que o legislador só consegue, efetivamente, alterar o sistema social caso se trate de situação-limite, marginal, na qual a percepção social acerca daquele comportamento é indiferente - um bom exemplo disso foi o artigo
65 da Lei $\mathrm{n}^{\circ}$ 9.503/97, que tornou obrigatório o uso do cinto de segurança.

A proposta deste artigo foi oferecer resposta a uma pergunta que é assaz ignorada pelo núcleo duro do campo jurídico. No entanto, responder a ela parece ser de suma relevância: será a relação entre Direito (lei) e sociedade uma via de mão dupla, na qual haja trocas constantes e volumosas em ambas as direções? Ou seria unilateral a influência, sendo a sociedade a determinar o direito (Ross, 2000) ou o Direito a sociedade (como parecem pretender os jusfilósofos que esperam da lei solução para todas as mazelas humanas)? A resposta que oferecemos é haver influências recíprocas, não em um modelo simplificador, mas com a lei sendo apenas um vetor em um emaranhado. E, dependendo da disposição dos demais vetores, a lei pode alterar drasticamente o comportamento social ou ser sumariamente ignorada. Nominamos essa proposta "influência marginal" do Direito positivo.

No concernente ao Realismo Jurídico, precisa-se considerar que está no próprio cerne de uma metodologia empiricista a impossibilidade de propor declarações a priori. Portanto, se aceitamos essa episteme como guia de nossa pesquisa, precisar-se-ia, também, aceitar a impossibilidade de declarar o que a lei é, de forma absoluta e universal. Em oposição às soluções a priori, poderíamos avaliar cada situação concreta a partir dos indicadores de realidade disponíveis. Em outras palavras, certas normas podem indicar decisões civilizatórias; outras podem atuar como vetores que buscam e sucedem - ou não - afetar o sistema social; outras normas, ainda, podem ser fruto de mera retórica, não representando nem decisão civilizatória nem vetor, mas sendo apenas um discurso derivado dos interesses políticos do legislador, desprovido de substância. 


\section{Referências}

Aímola, L. Uma introdução à ciência ambiental: complexidade socioambiental, auto-organização e interdisciplinaridade. In: Abramovay, R. (Org.). Construindo a ciência ambiental. São Paulo: Annablume-Fapesp, 2002. p. 151-174.

Ardoino, J. A complexidade. In: Morin, E. (Org.). A religação dos saberes: o desafio do século XXI. Rio de Janeiro: Bertrand Brasil, 2010.

Bobbio, N. Da estrutura à função: novos estudos de teoria do direito. Tradução de Daniela Baccaccia Versani. Barueri-SP: Manole, 2007.

Fadul, D.; Souza-Lima, J. E. Contornos do conhecimento ambiental: uma contribuição do realismo jurídico. Revista Jurídica, 3(32), 383-403, 2013. Disponível em: <http:// revista.unicuritiba.edu.br/index.php/RevJur/article/ view/693/519>.

Fadul, D. M.; Souza-Lima, J. E. O campo do conhecimento jurídico e os desafios da interdisciplinaridade. Revista Orbis Latina, 4, 63-74, 2014.

Frege, G. On Sense and Reference. ["Über Sinn und Bedeutung"]. Zeitschrift für Philosophie und philosophische Kritik, 100, 25-50, 1892. Disponivel em: <http://philo.ruc. edu.cn/logic/reading/On\%20sense\%20and\%20reference. pdf $>$. Acesso em: 25 dez. 2016.

Mankiw, N. G. Introdução à Economia. Rio de Janeiro: Campus, 2001.
Narayan-Parker, D. Empowerment and Poverty Reduction. Washington: The World Bank Press, 2002.

Norgaard, R. B. Development betrayed: the end of progress and a coevolutionary revisioning of the future. London and New York: Routledge, 1994.

Ross, A. Direito e Justiça. São Paulo: Edipro, 2000.

Simmons, A. H. The Neolithic Revolution in the Near East. Arizona: The University of Arizona Press, 2007.

Souza-Lima, J. E. Conhecimento ambiental no Brasil: indagações sobre o novo campo. Texto conclusivo de estágio pós-doutoral junto ao Programa de Pós-Graduação em Meio Ambiente e Desenvolvimento (PPGMADE-UFPR), outubro de 2012.

Souza-Lima, J. E. Contornos do conhecimento ambiental: uma contribuição da Sociologia. Acta Scientiarum. Human and Social Sciences, 35, 149-159, 2013.

Souza-Lima, J. E.; Knechtel, M. R. Multiculturalismo e Educação Ambiental: dois campos de coexistêcia das racionalidades culturais e ambientais. In: Morales, A. G. (Org.). Educação ambiental e multiculturalismo. Ponta Grossa: Editora UEPG, 2012. p. 27-36.

Von Bertalanffy, L. Perspectives on General Systems Theory. New York: George Braziller, 1975.

Wiener, N. Cybernetics or Control and Communication in the Animal and the Machine. Paris: Hermann \& Cie., 1948. 